\title{
Successful Arthroscopic Treatment of Pigmented Villonodular Synovitis of the Knee in a Patient with Congenital Deficiency of Plasminogen Activator Inhibitor-1 and Recurrent Haemarthrosis
}

\author{
Hideto Matsui a Yukihiro Takahashi ${ }^{a}$ Takeshi Matsunaga ${ }^{a}$ \\ Taeko Tanaka-Horie $^{a}$ Hideki Minowa $^{a}$ Mitsuhiko Sugimoto $^{a}$ \\ Ryuichi Tsukino ${ }^{c}$ Yoshio Mii ${ }^{b}$ John Giddings ${ }^{d}$ Akira Yoshioka ${ }^{a}$ \\ aDepartment of Pediatrics and ${ }^{b}$ Division of Central Operation, Nara Medical University \\ Hospital, Kashihara, and 'Department of Pediatrics, Arita City Hospital, Arita, Japan; \\ ${ }^{\mathrm{d}}$ Department of Haematology, University of Wales College of Medicine, Cardiff, UK
}

\section{Key Words}

Congenital deficiency of plasminogen activator inhibitor-1 Pigmented villonodular synovitis - Tranexamic acid

\begin{abstract}
We report the arthroscopic treatment of pigmented villonodular synovitis (PVNS) in a 13year-old Japanese boy with congenital partial deficiency of plasminogen activator inhibitor-1 (PAI-1). He was admitted to our hospital with recurrent haemarthrosis of his right knee. Characteristic abnormalities of fibrinolysis included shortened euglobulin lysis time, low PAl-1 activity and low PAI-1 antigen levels. In addition, levels of 'active PAI' in the
\end{abstract}

plasma, which is a measure of total PAI bound to exogenous plasminogen activator, were very low. These parameters remained low after venous occlusion. The diagnosis of PVNS was established by synovial membrane biopsy, and arthroscopic synovectomy was performed with adjuvant administration of intravenous tranexamic acid. Subsequent bleeding episodes have been well controlled by oral administration of tranexamic acid on demand.

\begin{tabular}{ll}
\hline KARGER & ○ 2001 S. Karger AG, Basel \\
Fax +41 61306 12 34 & 0301-0147/01/0312-0106\$17.50/0 \\
$\begin{array}{l}\text { E-Mail karger@karger.ch } \\
\text { www.karger.com }\end{array}$ & $\begin{array}{l}\text { Accessible online at: } \\
\text { www.karger.com/journals/hae }\end{array}$
\end{tabular}

Yukihiro Takahashi, MD

Department of Pediatrics, Nara Medical University

840 Shijo-Cho, Kashihara, Nara 634-8522 (Japan)

Tel. +8174429 8881, Fax +81744249222

E-Mail nicuyuki@naramed-u.ac.jp 


\section{Introduction}

The vascular fibrinolytic system is regulated by two principal physiological inhibitors, plasminogen activator inhibitor-1 (PAI1) and alpha 2-plasmin inhibitor. PAI-1 is a member of the serine protease inhibitor superfamily and inhibits the conversion of plasminogen, by tissue-type or urokinase-type plasminogen activator, to the active enzyme plasmin $[1,2]$. It is found in plasma, platelets, endothelial cells, hepatoma cells and fibrosarcoma cells [3]. In the plasma, PAI-1 is mainly derived from vascular endothelial cells [4-6] and partially from platelets [7-9]. A deficiency of PAI-1 leads to an enhancement of plasminogen activation and causes a bleeding tendency due to relatively unrestrained fibrinolysis. Congenital PAI-1 deficiency is a rare disorder and is usually managed effectively with oral tranexaminc acid [10-14]. We have recently reported four unrelated cases [15]. In the present study, we investigated the case of another Japanese boy with congenital partial deficiency of plasma PAI-1 who experienced recurrent haemarthrosis due to pigmented villonodular synovitis (PVNS).

\section{Methods}

\section{Blood Collection}

Informed consent was obtained from the patient, his family and normal volunteers in accordance with local ethical guidelines. Blood samples were collected without the use of a tourniquet from each individual after resting in a recumbent position for $10 \mathrm{~min}$ between 8.00 a.m. and 10.00 a.m. Venous blood was anticoagulated with 0.1 vol $3.8 \%$ sodium citrate. The samples were centrifuged at $3,000 \mathrm{rpm}$ for $15 \mathrm{~min}$ at $4{ }^{\circ} \mathrm{C}$. The upper two thirds of the plasma layer were used for various clotting and fibrinolysis measurements.

Clotting and Fibrinolysis Studies

Standard haemostasis tests were performed using routine laboratory procedures. Von Willebrand factor antigen was measured using the Asserachrom vWF Kit (Roche Diagnostics, Tokyo, Japan) and Ristocetin cofactor activity was assayed using von Willebrand Reagent (Hoechst-Boehringer Diagnostics, Tokyo, Japan). Factor XIII antigen was measured using a latex agglutination method (Latex Kit FXIII; Teikoku Zoki, Tokyo, Japan). This method detects subunit A of factor XIII.

\section{Euglobulin Clot Lysis Time}

Euglobulin fractions of plasma were prepared by adding 19 parts of $3 \mathrm{mM}$ acetic acid (pH 3.6) to one part of plasma, allowing the reaction mixture to stand at $4^{\circ} \mathrm{C}$ for $1 \mathrm{~h}$, and then centrifuging at 3,000 rpm for $10 \mathrm{~min}$ at $4^{\circ} \mathrm{C}$. The euglobulin fraction was dissolved in 1.5 parts of the original plasma volume of $20 \mathrm{mM}$ borate saline buffer ( $\mathrm{pH}$ 7.8). The specimen was clotted by adding 0.3 parts of the original plasma volume of $20 \mathrm{U} / \mathrm{ml}$ human thrombin (Welfide Corporation, Osaka, Japan) and lysis time was monitored at $37^{\circ} \mathrm{C}$. Alpha 2-plasmin inhibitor ( $\alpha 2-\mathrm{PI})$ activity and plasminogen activity were measured using chromogenic substrate methods (Testzym APL-2 and Testzym PLG-2, respectively; Dai-ichi Pure Chemicals, Tokyo, Japan). Tissue plasminogen activator (tPA) antigen and PAI-1 antigen were measured by ELISA (Imulyse tPA and Imulyse PAI-1, respectively; Biopool, Umeå, Sweden). PAI activity was measured by chromogenic assay (Spectrolyse PAI: Biopool). In outline, an excess of single-chain tPA was added to the plasma sample. This reacted with the sample PAI resulting in inactivation. The residual tPA activity was then measured by colorimetry in the following manner. First, $1 \mathrm{M}$ acetic acid buffer solution ( $\mathrm{pH}$ 3.9) was added. Then, the sample was heated at $37^{\circ} \mathrm{C}$ for $20 \mathrm{~min}$ to degrade the $\alpha 2$-PI. Finally, Glu-plasminogen was added followed by a specifically synthesized chromogenic substrate $(D-$ But-CHT-Lys-pNA) to measure the plasmin that had been generated. PAI activity was inversely proportional to the residual tPA. In addition we utilized a new PAI assay kit (TDC-88; kindly donated by Teijin Corporation, Japan) to measure the tPA-PAI complex and the total residual PAI in the presence of exogenous tPA (so-called 'active PAI'). In this assay, the tPA-PAI complex was first assessed in plasma by sandwich ELISA using a monoclonal anti-PAI as capture antibody followed by a peroxidase-labelled polyclonal antitPA as second antibody. The assay was then repeated on the same plasma sample after the addition of exogenous tPA and acidification as above. The difference between the two results (assay 2 - assay 1) provided an index of the total free PAI in the plasma sample bound to the added tPA. All ELISAs were performed using an 
Table 1. Fibrinolytic parameters in the propositus and his parents

\begin{tabular}{lcccc}
\hline & Patient & Father & Mother & Normal \\
\hline Euglobulin lysis time, $\mathrm{h}$ & 1.50 & $>5.00$ & $>5.00$ & $>2.00$ \\
\hline tPA & & & & \\
tPA activity, U/ml & 0.69 & 0.67 & 0.76 & $0.5-4.3$ \\
tPA antigen, ng/ml & 6.06 & 3.25 & 3.43 & $3-13$ \\
\hline PAI-1 & & & & \\
PAI-1 activity, IU/ml & 1.02 & 15.60 & 3.45 & $8-22$ \\
Active PAI-1, ng/ml & 3.62 & 10.86 & 5.30 & $4-24$ \\
$\quad$ PAI-1 antigen, ng/ml & 3.68 & 15.97 & 5.66 & $7-37$ \\
\hline Plasminogen activity, \% & 94 & 85 & 88 & $80-120$ \\
a2-PI activity, \% & 95 & 88 & 92 & $80-130$ \\
\hline
\end{tabular}

The normal values were determined from 20 healthy adults. automated enzyme immunoassay device (ELISA F300; International Reagents, Kobe, Japan).

\section{Venous Occlusion Tests}

Initial samples (before) were obtained as described above. A sphygmomanometer cuff was placed on the upper arm and a pressure midway between the systolic and diastolic blood pressure was applied for $5 \mathrm{~min}$. Second blood samples (after) were collected immediately (without using a tourniquet) from below the point of applied pressure. The euglobulin lysis times, tPA antigen levels, PAI-1 antigen levels, PAI activity and tPA-PAI-1 complexes were measured simultaneously from these 'before' and 'after' samples.

\section{Case Report}

A 13-year-old Japanese boy was admitted to our hospital suffering from recurrent haemarthrosis in his right knee of unknown cause. He had repeated joint aspiration without success. His right knee was remarkably swollen and fluctuation with mild tenderness was palpable. His walking was slightly disturbed. His clinical history indicated that at birth no umbilical bleeding was recorded. He had suffered from recurrent subcutaneous haematomas after trauma from early infancy and from prolonged bleeding after a tooth extraction. From the age of 10 years he had recurrent spontaneous haemarthrosis. Haemostatic tests including all coagulation assays, von Willebrand factor and platelet func- tion analysis were performed by standard methods and were within normal limits (not shown). Table 1 illustrates the results of the fibrinolytic tests. The plasma levels of tPA activity and antigen were within normal limits. $\alpha 2$-PI and plasminogen levels were also within normal limits. The euglobulin lysis time was shortened and plasma PAI activity and PAI-1 antigen were lower than normal. The plasma level of total active PAI, which represents the binding capacity of total free PAI to exogenous tPA, was also below normal limits. Furthermore, euglobulin lysis time was not affected by venous stasis, and levels of PAI- 1 activity and active PAI were reduced further after venous occlusion (table 2). In contrast, PAI-1 antigen increased, and the plasma levels of tPA and the tPA-PAI complex were elevated to the same extent as in normal controls after the venous occlusion test. Based on these findings, we established the diagnosis of congenital partial deficiency of PAI-1. His mother was found to have low levels of PAI activity and PAI-1 antigen, whereas those of his father were normal. Both parents were asymptomatic.

Arthroscopy and synovial membrane biopsy were performed with adjuvant intravenous administration of tranexamic acid $(20 \mathrm{mg} / \mathrm{kg})$. Histological findings showed PVNS (fig. 1a, b). Arthroscopic synovectomy was performed subsequently, again with intravenous administration of tranexamic acid $(20 \mathrm{mg} / \mathrm{kg})$. During the surgical procedure, 3 units $(30 \mathrm{ml} / \mathrm{kg})$ of fresh frozen plasma and 1 unit $(400 \mathrm{ml})$ of red cell concentrate in mannitol-adenine-phosphate solution were infused because of blood loss $(800 \mathrm{ml})$. Postoperative manage-
108

Haemostasis 2001;31:106-112 
Table 2. Changes of euglobulin lysis time, tPA activity and antigen, tPA-PAI complex, PAI-1 activity, active PAI-1 and PAI-1 antigen induced by venous occlusion in the propositus and his parents

\begin{tabular}{|c|c|c|c|c|c|c|c|c|}
\hline & \multicolumn{2}{|c|}{ Patient } & \multicolumn{2}{|c|}{ Father } & \multicolumn{2}{|c|}{ Mother } & \multicolumn{2}{|l|}{ Normal } \\
\hline & before & after & befor & e after & befor & re after & before & after \\
\hline Euglobulin lysis time, $\mathrm{h}$ & 1.50 & 1.50 & $>5.00$ & $>5.00$ & $>5.00$ & $>5.00$ & $>2.00$ & $>2.00$ \\
\hline \multicolumn{9}{|l|}{$\mathrm{tPA}$} \\
\hline tPA activity, $\mathrm{U} / \mathrm{ml}$ & 0.69 & 2.36 & 0.67 & 1.95 & 0.76 & 1.27 & $0.5-1.5$ & $1.0-5.5$ \\
\hline tPA antigen, $\mathrm{ng} / \mathrm{ml}$ & 6.06 & 9.47 & 3.25 & 9.49 & 3.43 & 8.59 & $3-13$ & $5-10$ \\
\hline tPA-PAI-1 complex, ng/ml & 4.25 & 9.93 & 8.84 & 9.48 & 5.08 & 9.88 & $4-10$ & $5-14$ \\
\hline \multicolumn{9}{|l|}{ PAI-1 } \\
\hline PAI-1 activity, IU/ml & 1.02 & 0.49 & 15.60 & 9.83 & 3.45 & 3.32 & $13-18$ & $10-18$ \\
\hline Active PAI-1, ng/ml & 3.62 & 1.29 & 10.86 & 9.94 & 5.30 & 3.30 & $5-12$ & $5-9$ \\
\hline PAI- 1 antigen, $\mathrm{ng} / \mathrm{ml}$ & 3.68 & 7.61 & 15.97 & 21.89 & 5.66 & 9.01 & $8-37$ & $15-38$ \\
\hline
\end{tabular}

Blood was obtained from 6 normal healthy adults and at the same time from the patient's family.

ment included oral administration of tranexamic acid $(20 \mathrm{mg} / \mathrm{kg}$ ) for 7 days without the need for further blood transfusion. After the operation, his plasma level of PAI-1 remained low. Bleeding episodes, including joint bleeding and bleeding after dental extraction, have since been well controlled by oral administration of tranexamic acid $(20 \mathrm{mg} / \mathrm{kg})$ on demand.

\section{Discussion}

Haemorrhagic disorders due to congenital disorders of primary hyperfibrinolysis are rare. Hereditary PAI-1 deficiency causes a lifelong bleeding tendency and demonstrates an autosomal dominant mode of inheritance. Schleef et al. [10] described the first case of hyerfibrinolysis due to congenitally decreased function of PAI-1, and subsequently, Dieval et al. [11], Lee et al. [12], Fay et al. [13], Takahashi et al. [14] and Minowa et al. [15] reported similar patients. Bleeding symptoms are less severe than in other hereditary fibrinolytic disorders such as $\alpha 2$-PI deficiency [16] and are often associated with delayed bleed- ing after transient haemostasis, especially after surgical procedures or tooth extractions. Spontaneous haemarthroses are very rare in these patients. The present report describes a new patient with congenital partial PAI-1 deficiency. Laboratory data revealed no other abnormality of coagulation factors or platelet function. The venous occlusion test showed that the IPA response was normal. There was a modest rise in PAI antigen, however, and an increase in tPA-PAI-1 complexes after venous stasis. In addition, PAI-1 activity determined by a new assay measuring residual total active PAI in the presence of exogenous tPA was depressed after venous occlusion. These findings indicate that some PAI-1 was released into the circulation in response to the vascular challenge and suggest that the defect in this case represented a partial deficiency of PAI-1 rather than an absolute deficiency of the inhibitor. The level of circulating PAI-1 required to maintain normal haemostasis is not known, and our patient suffered from a significant bleeding diathesis in the presence of a 

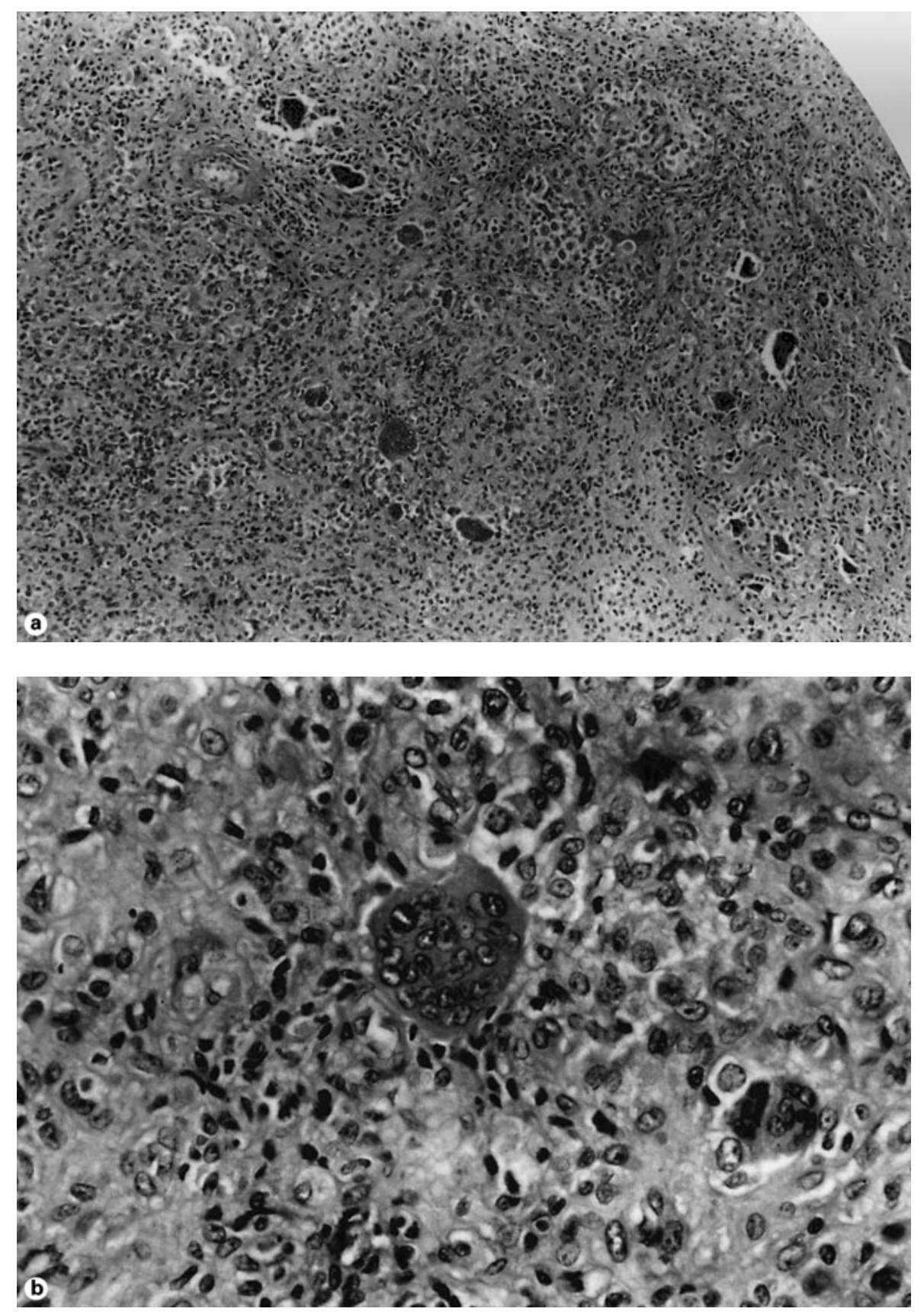

Fig. 1a, b. Photomicroscopic findings of synovial membrane biopsy. Broad sheets of histiocytes with scattered lymphocytes and osteoclast-like giant cells, so-called xanthoma cells, are evident. Some histiocytes contain hemosiderin. The diagnosis of localized PVNS was established. a Original magnification $\times 30$. b Original magnification $\times 140$. 
mild deficiency. Results in the mother were similar but were less marked than in the propositus. The father did not exhibit the abnormality and both parents were asymptomatic. The findings suggest an autosomal dominant mode of inheritance with variable penetrance. Further studies are required, however, to clarify the precise nature of the genetic defect PVNS is a benign proliferative disorder of the synovium of uncertain aetiology $[13,18]$. It occurs in two forms, diffuse and localized, either of which usually involves a single joint, commonly the knee. The annual incidence is 1.8 cases per million of the population and it is extremely rare in childhood. The clinical signs and symptoms are palpable soft tissue mass, joint swelling and other mechanical disturbances. Magnetic resonance imaging usually demonstrates key diagnostic features and the diagnosis is confirmed by histological examination of synovial biopsies [19]. Our case illustrated these typical clinical and his- topathological features. This is the first case to be reported of PVNS in congenital PAI-1 deficiency. Indeed, a search of the literature has failed to identify PVNS in association with any hereditary haemostatic defect. The diagnosis of PVNS remains a diagnostic challenge, however [20], and it seems possible that more extensive application of modern imaging techniques might reveal a greater incidence of this type of pathology in patients with coagulation disorders. A similar case involving haemarthrosis of the elbow in a patient with haemophilia A has recently been identified [Collins, P.W., pers. comm.]. The episodes of haemarthrosis of the knee in our patient were clearly aggravated by PVNS, and arthroscopic synovectomy has alleviated these symptoms. It may be that similar therapeutic interventions could be beneficial on a wider scale in the management of hereditary bleeding disorders.

\section{References}

1 Bachmann F: The plasminogenplasmin enzyme system; in Colman RW, Hirsh J, Marder VJ, Salzman EW (eds): Hemostasis and Thrombosis: Basic Principles and Clinical Practice, ed 3. Edinburgh, Lippincott, 1993, pp 1592-1622.

2 Loskutoff DJ, Sawdey M, Mimuro J: Type 1 plasminogen activator inhibitor. Prog Hemost Thromb 1989;9: 87-115.

3 Ginsburg D, Zeheb R, Yang AY, Rafferty UM, Andreasen PA, Nielsen L, Dan K, Lebo RV, Gelehrter TD: cDNA cloning of human plasminogen activator-inhibitor from endothelial cells. J Clin Invest 1986; 78:1673-1680.

4 Erickson LA, Schleef RR, Ny T, Loskutoff DJ: The fibrinolytic system of the vascular wall. Clin Haematol 1985; 14:513-530.
5 Erickson LA, Hekman CM, Loskutoff DJ: The primary plasminogen activator inhibitors in endothelial cells, platelets, serum and plasma are immunologically related. Proc Natl Acad Sci USA 1985;82:87108714.

6 Van Mourik JA, Lawrence DA, Loskutoff DJ: Purification of an inhibitor of plasminogen activator (antiactivator) synthesized by endothelium cells. J Biol Chem 1989;259:1491414921.

7 Erickson LA, Ginsberg MH, Loskutoff DJ: Detection and partial characterization of an inhibitor of plasminogen activator in platelets. $\mathbf{J}$ Clin Invest 1984;74:1465-1472.

8 Booth NA, Anderson JA, Bennett B: Platelet release protein which inhibits plasminogen activators. J Clin Pathol 1985;38:825-830.
9 Sprengers ED, Akkerman JWN, Jansen BG: Blood platelet plasminogen activator inhibitor: Two different pools of endothelial cell type plasminogen activator inhibitor in human blood. Thromb Haemost 1986;55:325-329.

10 Schleef RR, Higgins DL, Pillemer E, Levitt LJ: Bleeding diathesis due to decreased functional activity of type 1 plasminogen activator inhibitor. $\mathrm{J}$ Clin Invest 1989;83:1747-1752.

11 Dieval J, Nguyen G, Gress S, Delobel J, Kruithof EKO: A lifelong bleeding disorder associated with a deficiency of plasminogen activator inhibitor type 1. Blood 1991;77: 528-532.

12 Lee MH, Vosburgh E, Anderson K, McDonagh J: Deficiency of plasma plasminogen activator inhibitor 1 results in hyperfibrinolytic bleeding. Blood 1993;81:2357-2362. 
13 Fay WP, Shapiro AD, Shih JL, Schleef RR: Complete deficiency of plasma plasminogen-activator inhibitor type 1 due to a frame shift mutation. N Engl J Med 1992;327: 1729-1733.

14 Takahashi Y, Tanaka T, Minowa H, Ookubo Y, Sugimoto M, Nakajima M, Miyauchi Y, Yoshioka A: Hereditary partial deficiency of plasminogen activator inhibitor-1 associated with a lifelong bleeding tendency. Int J Hematol 1996;64:61-68.
15 Minowa H, Takahashi Y, Tanaka T, Naganuma K, Ida S, Maki I, Yoshioka A: Four cases of bleeding diathesis in children due to congenital plasminogen activator inhibitor-1 deficiency. Haemostasis 1999;29: 286-291.

16 Takahashi Y, Tanaka T, Nakajima M, Yoshioka A, Fukui H, Miyauchi Y, Mii Y, Tamai S: Intramedullary multiple hematomas in siblings with congenital alpha-2-plasmin inhibitor deficiency: Orthopedic surgery with protection by tranexamic acid. Haemostasis 1991;21:321-327.

17 Jaffe HL, Liechtenstein L, Sutro CJ: Pigmented villonodular synovitis, bursitis and tenosynovitis. Arch Pathol 1941;31:731-765.
18 Vedantam R, Strecker WB, Schoenecker PL, Madrigal LS: Polyarticular pigmented villonodular synovitis in a child. Clin Orthop 1998;348: 208-211.

19 Jelinek JS, Kransdorf MJ: Imaging of pigmented villonodular synovitis with emphasis on MR imaging. AJR Am J Roentgenol 1989;152:337342.

20 Frassica FJ, Bhimani MA, McCarthy EF, Wenz J: Pigmented villonodular synovitis of the hip and knee. Am Fam Physician 1999;60: 1404-1410. 